\title{
Lexical and grammatical development in children at family risk of dyslexia from early childhood to school entry: a cross-lagged analysis
}

\author{
Ømur CAGLAR-RYENG ${ }^{1 *}$, Kenneth EKLUND ${ }^{2}$, and Trude NERGÅRD-NILSSEN ${ }^{1}$ \\ ${ }^{1}$ UiT - The Arctic University of Norway, Norway and ${ }^{2}$ University of Jyväskylä, Finland \\ ${ }^{*}$ Corresponding author: Department of Education, UiT - The Arctic University of Norway, 9037 Tromsø, \\ Norway. E-mail: omuer.caglar-ryeng@uit.no
}

(Received 8 February 2018; revised 12 January 2019; accepted 7 May 2019; first published online 18 July 2019)

\begin{abstract}
The aim of this study was to examine (a) the development of vocabulary and grammar in children with family-risk (FR) of dyslexia and their peers with no such risk (NoFR) between ages 1;6 and 6;0, and (b) whether FR-status exerted an effect on the direction of temporal relationships between these two constructs. Groups were assessed at seven time-points using standardised tests and parental reports. Results indicated that although FR and NoFR children had a similar development in the earlier years, the FR group appeared to perform significantly more poorly on vocabulary at the end of the preschool period. Results showed no significant effect of FR status on the cross-lagged relations between lexical and grammatical skills, suggesting a similar developmental pattern of cross-domain relations in both groups. However, FR status seemed to have a significantly negative association with vocabulary and grammar scores at age 6;0, resulting in language outcomes in favour of NoFR children.
\end{abstract}

Keywords: dyslexia; vocabulary; grammar; lexical bootstrapping; syntactic bootstrapping

\section{Introduction}

It has long been known that dyslexia runs in families, and the consensus view is that dyslexia is a multifactorial disorder with a complex interaction of genetic factors with environmental influences (Snowling \& Melby-Lervåg, 2016; van Bergen, van der Leij, \& de Jong, 2014). Over the past thirty years, research on children with familial risk of dyslexia (FR) has shown that FR children are at heightened risk of experiencing reading difficulties (e.g., Snowling, Gallagher, \& Frith, 2003; Torppa, Lyytinen, Erskine, Eklund, \& Lyytinen, 2010). A recent review by Snowling and Melby-Lervåg (2016) has furthermore reported that the course of language development might

(C) The Author(s) 2019. This is an Open Access article, distributed under the terms of the Creative Commons Attribution licence (http://creativecommons.org/licenses/by/4.0/), which permits unrestricted re-use, distribution, and reproduction in any medium, provided the original work is properly cited. 
differ between these children and their peers without family risk of dyslexia (NoFR) in the preschool years. Although FR children have impairments primarily in the phonological domain, these children, as a group, tend to score lower than their NoFR peers on tasks assessing wider oral language skills, including vocabulary and grammar (e.g., Gallagher, Frith, \& Snowling, 2000; van Viersen et al., 2018).

The preschool language problems of children with dyslexia show some similarities to those detected in children with developmental language disorder (DLD, which has replaced the term Specific Language Impairment; Bishop \& Snowling, 2004; Bishop et al., 2017). Recently, it has been reported that nearly one-third of preschool children with FR met the criteria for a diagnosis of DLD. This demonstrates the importance of recognising the continuities between reading and language disorders and keeping an eye on FR children's language development from early on (Nash, Hulme, Gooch, \& Snowling, 2013). A great deal of evidence suggests that reading (and spelling) disorders are strongly associated with underlying delays and difficulties with language development (Snowling \& Hulme, 2012). It is therefore particularly important to capture the early development of vocabulary and grammar and the interplay between them in children who have a family history of dyslexia. The current study compared the lexical and grammatical development of FR children to that of age-matched NoFR controls from age 1;6 up to school entry to gain more insight into the nature of the developmental patterns observed in these two language domains. To our knowledge, this is the first longitudinal study to examine whether family risk has an impact on the cross-lagged relationships between these domains over the course of the preschool years.

\section{The role of broader language skills in literacy development}

Developmental dyslexia is a learning disorder which mainly affects the ability of reading and spelling. An underlying weakness in phonological (speech sound) processing has been suggested to be the primary cause of word-level reading impairments in dyslexia (Snowling \& Hulme, 2012). Studies on reading development carried out in alphabetical languages have provided converging evidence that phoneme awareness and letter knowledge are two of the most crucial predictors of variation in children's learning to decode print, both in irregular (e.g., English) and regular (e.g., Norwegian) orthographies (Lervåg, Bråten, \& Hulme, 2009; Thompson et al., 2015). However, the ultimate goal of reading is to understand written text, which requires access to the meanings of words and higher-level processes such as sentence integration and inferencing (Snowling \& Hulme, 2012). In early development, comprehension strongly depends on word decoding skills (Hulme, Nash, Gooch, Lervåg, \& Snowling, 2015). When children get older, however, the correlation between reading comprehension and decoding skills tends to decrease, whereas the correlation between reading comprehension and oral language skills, including vocabulary and grammar, increases (Hulme et al., 2015). Therefore, literacy development depends not only on the phonological skills but also on the broader oral language skills that children bring to the task of reading.

Recent longitudinal studies of FR children have confirmed the essential role of early language skills as a foundation for literacy development across languages (e.g., Dutch: van Viersen et al., 2018; English: Carroll, Mundy, \& Cunningham, 2014; Hulme et al., 2015; Snowling, Gooch, McArthur, \& Hulme, 2018; Finnish: Torppa et al., 2010). In their study with English-speaking FR children, Hulme et al. (2015) demonstrated that language skills at age $3 ; 6$ predicted the preliteracy skills 
(i.e., phoneme awareness, rapid naming, and letter-sound knowledge) at age 4;6, which in turn predicted word-level literacy at age 5;6. Interestingly, they also found that oral language skills assessed at age 3;6 had a direct influence on reading comprehension at age $8 ; 6$, leading the authors to argue that these skills might have a causal effect on reading comprehension development. Van Viersen et al. (2018) reported similar findings from Dutch-speaking FR children, showing that the two pathways toward reading comprehension, that is, one through preliteracy skills and word decoding and the other through later language abilities, both built on early oral language skills.

In summary, studies conducted across languages show that reading (and spelling) disorders are strongly associated with underlying delays and difficulties with language development (Hulme et al., 2015). Deficient skills in the phoneme awareness and letter knowledge of FR children are well documented in the literature (Snowling \& Melby-Lervåg, 2016). However, the early lexical and grammatical skills of FR children are relatively less examined, and therefore it is of interest to observe the development of these skills from early on in this group of children. Moreover, to our knowledge, Norwegian-speaking preschoolers with FR have not been previously studied on this topic. By doing this, before the onset of formal schooling, we could determine whether these children may be at higher risk of facing reading difficulties, not only in decoding but also in reading comprehension.

\section{Lexical and grammatical development in FR children}

Prospective studies of English-speaking children carried out by Snowling and colleagues (2003), and by Carroll et al. (2014) show that FR children who go on to develop dyslexia had lower vocabulary and grammar scores at ages $4 ; 0$ and 6;0 compared to both unaffected FR children and NoFR children (i.e., the control group). Likewise, van Viersen et al. (2017) reported that unaffected FR children and NoFR children had the same levels of receptive and expressive vocabulary skills between ages 17 and 35 months. The overall vocabulary of affected FR children (i.e., FR children with dyslexia) was poorer compared to both groups.

On the other hand, studies that have contrasted FR children with NoFR children in the preschool years evidence a range of broader language skills in FR children with group means, which are not always significantly different from the typically developing controls. For example, in a Finnish family risk study by Lyytinen et al. (2004), NoFR children had a slightly higher, but non-significant, total word production than FR children at age 18 months, whereas a Dutch study by Koster et al. (2005) revealed a significant difference between the FR and NoFR groups for total word production at 17 months. Another Dutch family study reported that the NoFR group had significantly larger vocabularies than FR children only at 19-20 months, with no significant group differences otherwise detected between 17 months and age 2;11 (Chen, Wijnen, Koster, \& Schnack, 2017). Further, the English-speaking FR children in the Nash et al. (2013) study performed significantly worse than their NoFR peers on a grammatical inflections test at age 3;6, but when tested at age $4 ; 6$, the group-level differences were no longer significant. In contrast, Lyytinen and Lyytinen (2004) reported vocabulary delays and deficits in inflectional morphology, which became more evident with increasing age, in Finnish FR children. Although the FR group did not differ from the NoFR group significantly at the first two assessment points (ages 2;0 and 2;6), a significant group-level difference was observed at age $3 ; 6$ and remained at age 5;0. 
Overall, these results indicate that the onset and persistence of language problems in FR children vary across studies. The variation in oral language skills between FR samples may have several reasons. As mentioned earlier, a line of research has established that there is a large overlap between dyslexia and DLD, probably due to shared cognitive and aetiological risk factors influencing both disorders (e.g., Catts, Adlof, Hogan, \& Weismer, 2005; Nash et al., 2013; Snowling \& Hulme, 2012). Bishop and Snowling (2004) proposed a two-dimensional model in which phonological and non-phonological (i.e., semantics, syntax, discourse) skills are separated. The authors hypothesise that phonological deficits underlie both dyslexia and DLD, but children with DLD would also show deficits in broader oral language skills. Along these lines, Snowling and Melby-Lervåg (2016) argue that the proportion of children with language impairments in FR samples could explain group-level differences in linguistic domains to varying degrees.

Furthermore, a recent longitudinal study by Snowling, Duff, Nash, and Hulme (2016) followed children who were initially classified as having either family risk for dyslexia or language impairment, from age 3;9 to age $8 ; 1$. In this study, in addition to the two groups of children, one with resolving and one with persisting language impairments, a third group was identified. The children in the third group had had late-emerging language delays detected at age 8;1. Children in this group had average oral language abilities in preschool, but developed language problems in middle childhood. Interestingly, a high proportion of these children were at family risk for dyslexia, suggesting a significant association between the late-onset trajectory and a family history of literacy problems. In a similar vein, Zambrana, Pons, Eadie, and Ystrom (2014), who followed children from ages $3 ; 0$ to 5;0, reported that children who developed late-emerging language difficulties at age 5;0 typically had a family history of reading impairments. These latter findings emphasise the importance of following FR children's language skills from the early years through to school age to track possible delays in linguistic growth.

Differences in native languages might also explain the variations in findings between studies regarding the ages at which FR and NoFR children differ in vocabulary and grammar knowledge. The children in the present study are native speakers of Norwegian, which is a Germanic language with a similar syntactic and morphological structure to English. For example, verbs are divided in two classes (regular vs. irregular) and inflected for tense, mood, and voice. The Norwegian lexicon is predominantly Germanic, but also includes loan words from other languages (Simonsen, Kristoffersen, Bleses, Wehberg, \& Jørgensen, 2014). Research on the longitudinal development of lexical and grammatical skills in toddlers and young children acquiring Norwegian has been sparse (Simonsen et al., 2014). Our study will partly fill this void by studying vocabulary and grammar knowledge in NoFR and FR children, respectively, at ages $1 ; 6,2 ; 0,2 ; 6,3 ; 0,3 ; 6,4 ; 6$, and $6 ; 0$. It will furthermore add to earlier English and Finnish studies by investigating the development of these skills in the Norwegian sample of FR children. And finally, by making the most of the longitudinal nature of the data, this study was taken to examine the possible interaction between lexicon and grammar across time, and whether FR status has an impact on the cross-lagged relations between the two constructs.

\section{Links between vocabulary and grammar in the preschool years}

Children typically produce their first words somewhere at age 10-12 months, and start combining words at age 16-20 months (Bates \& Goodman, 2001). Although most 
children master the essential grammatical structures of their native language by ages $3 ; 0$ to $3 ; 6$, some specific properties of grammar, and lexicon-syntax interactions, continue to develop through the preschool years (Bates \& Goodman, 2001). A central question prompted by this description is whether and how vocabulary and grammar relate to one another across development. Earlier studies have provided empirical evidence that there is a strong and positive correlation between measures of lexical and grammatical skills in early language acquisition (i.e., up to ages 2;6-3;0). In a seminal longitudinal study of English-speaking toddlers, Bates, Bretherton, and Snyder (1988) found a correlation of .83 between vocabulary size at 20 months and grammar measured using the mean length of utterance (MLU) at 28 months, pointing to a strong interdependency between these two domains. Subsequent studies using parental reports on typically and atypically developing children (e.g., Bates \& Goodman, 2001; Braginsky, Yurovsky, Marchman, \& Frank, 2015; Marchman \& Bates, 1994; Thordardottir, Weismer, \& Evans, 2002) have corroborated these findings across various languages, lending support for the hypothesis that the emergence of syntactic and morphological structures in early language development depends on the extent of expressive vocabulary (i.e., the critical mass hypothesis; Marchman \& Bates, 1994).

The temporal ordering that early lexical development occurs prior to the onset of grammatical constructions is often accounted for by a mechanism referred to as lexical bootstrapping (e.g., Dale, Dionne, Eley, \& Plomin, 2000). According to this account, a sufficient number of content words is the necessary foundation to abstract the regularities and irregularities, which are required for the production of grammatical forms (Marchman, Martínez-Sussmann, \& Dale, 2004). However, as with any bivariate relationship, there is also a possibility that the tight link observed between vocabulary and grammar is due to the strong influence of grammatical growth on vocabulary learning. That is, children's growing grammatical knowledge can be seen to act as a driving force behind their lexical acquisition. This process, known as syntactic bootstrapping (Gleitman, 1990; Naigles, 1990; Naigles \& Swensen, 2007), suggests that children exploit morphological and syntactic cues in the linguistic input (e.g., the types of words that appear in certain parts of a sentence) to derive the meaning of novel words, and has been well documented in experiments with both infants and preschoolers (e.g., Bernal, Lidz, Millotte, \& Christophe, 2007; Naigles, \& Kako, 1993). The main assumption behind both the bootstrapping approaches is that there is a systematic relationship, though to varying degrees, between the properties of the lexical and the grammatical representations, and the child can detect and make use of the regularities that characterise the interaction between these two linguistic domains (Gleitman, 1990; Weissenborn \& Hohle, 2001). This assumption implies that the major role of bootstrapping mechanisms is to detect structural units and properties in the language input that can serve as constraints for further learning. Hence, it has been argued that bootstrapping mechanisms indeed function as a filter between input and learning to constrain the learning mechanisms in a linguistically relevant way, and that these learning mechanisms themselves can be of a general character, and are not necessarily domain-specific, such as statistical (distributional) learning (Hohle, 2009).

Statistical learning refers to the ability to implicitly detect recurring patterns and regularities in sensory input based on their frequency, variability, distribution, and co-occurrence probability to learn higher-order structure (Erickson \& Thiessen, 2015). The term 'statistical learning' was originally used to describe infants' 
sensitivity to the probability with which syllables co-occur, and their use this property to segment words from fluent speech (Thiessen, 2017). However, a seminal study of artificial language learning by Saffran and Wilson (2003) showed that young children could not only segment continuous speech into words, but also that they could extract syntactic rules from it. These results suggest that young children are able to move from surface structure to deeper structure as they track syllables to find words and then an underlying grammar to learn about phrasal units. Therefore, these results illustrate how learning at one level of analysis could potentially affect learning downstream (Romberg \& Saffran, 2010). Research on infants with FR of dyslexia has evidenced that family risk is strongly associated with a deficit in the perception and segmentation of speech, which supports the hypothesis that phonological deficits in dyslexia have their origins in poor sensitivity to speech stimuli (Lohvansuu, Hämäläinen, Ervast, Lyytinen, \& Leppänen, 2018; Snowling, Lervåg, Nash, \& Hulme, 2019). In their longitudinal study, Lohvansuu et al. (2018) documented that atypical brain responses to speech sounds in infancy could implicate a deficient development of phonological representations that later hindered access to lexicon in at-risk children. Likewise, Snowling et al. (2019) showed that deficits in speech perception were related with both poor language skills and poor reading in a sample of preschoolers with FR of dyslexia. These findings suggest that deficiencies in segmenting words from continuous speech may have long-term effects on later language development in at-risk children.

As stated earlier, bootstrapping mechanisms, which are compatible with the accounts of statistical leaning, underscore the role of distributional and structural information in the input. They also postulate interfaces between different linguistic domains, which may be responsible for parallel learning (Hohle, 2009). Therefore, given the existence of correspondences between syntax and semantics, one might expect to find positive correlations between the measures assessing them. However, concurrent correlations do not provide much information about the precise nature of the longitudinal link between lexical and grammatical development (e.g., temporal ordering) and the possible bootstrapping mechanisms underpinning this association. Despite the long-standing research interest, relatively few studies have addressed the directionality of the influence between words and grammar using analytical techniques testing the contribution of each aspect of language to the other in a longitudinal design (e.g., Dionne, Dale, Boivin, \& Plomin, 2003; Hoff, Quinn, \& Giguere, 2018; Moyle, Weismer, Evans, \& Lindstrom, 2007).

In a study of same-sex twin pairs between the ages of 2;0 and 3;0, Dionne et al. (2003) investigated the role of lexical and syntactic bootstrapping mechanisms and found that lexical knowledge at age 2;0 was related to grammatical level at age 3;0 (i.e., lexical bootstrapping), and that grammatical level at age 2;0 predicted lexical level at age 3;0 (i.e., syntactic bootstrapping), thus providing support for reciprocal influences between domains (i.e., bi-directional bootstrapping). Moyle et al. (2007) compared the lexical and grammatical growth in late-talking and control children and reported significant positive cross-domain correlations in both groups. However, in the late-talker group, there were weaker correlations between earlier grammar and later vocabulary size than between earlier vocabulary and later grammar, indicating predominantly lexical bootstrapping. Control children, on the other hand, exhibited lexical bootstrapping and syntactic bootstrapping more equally throughout the preschool years providing support for bi-directional links between the two domains. In contrast to the findings of Dionne et al. (2003) and Moyle et al. (2007), a recent 
longitudinal study examining vocabulary and grammar growth in Spanish-English bilingual children between ages 2;6 and 4;0 found no evidence for lexical or grammatical bootstrapping, despite the fact that the slopes of vocabulary and grammar growth were correlated within each language (Hoff et al., 2018). Finding no support for bootstrapping between the domains, the authors proposed that the effects of children's language-specific input on both lexical and grammatical development in each language could account for the correlated but uncoupled growth of these two domains.

\section{The current study}

Previous research provided evidence that developmental interdependencies between vocabulary and grammar may differ in typically and atypically developing children (Moyle et al., 2007). However, to our knowledge, no studies so far have examined whether FR status may have an effect on possible lexical and grammatical bootstrapping mechanisms in children with a family history of dyslexia. Utilising path analyses in MPLUS, in this study, we could separate the direct effects of the cross-lagged associations between vocabulary and grammar (lexical bootstrapping), and vice versa (syntactic bootstrapping), while taking into account the indirect effects via concurrent measures of vocabulary and grammar. To summarise, we aimed to compare the developmental trajectories of vocabulary and grammar skills in Norwegian FR and NoFR children and to explore the temporal relationship between the constructs from early years to school entry age (children in Norway start school the calendar year they turn six) by answering the following questions:

1. Do the FR and NoFR children differ in terms of their lexical and grammatical growth from age $1 ; 6$ to $6 ; 0$ ? It was hypothesised that we might not detect significant between-group differences in these domains because children in this study do not have a definite dyslexia status yet. Prior research suggests that since it is mainly the FR children with a later diagnosis of dyslexia who show below-average oral language skills in the preschool years, detecting significant differences at the group level might be dependent on the number of affected FR children in a given sample (van Viersen et al., 2018). On the other hand, emerging evidence revealed a significant association between late-onset language problems and family risk of dyslexia (Snowling et al., 2016). Thus, it was also hypothesised that group-level differences on language measures might be observed later in development (i.e., towards the end of the preschool period).

2. What is the pattern of the developmental interdependencies between lexical and grammatical domains across this period? Does FR status exert an effect on the relationships between vocabulary and grammar? Based on previous research, it was predicted that lexical bootstrapping would be observed in the earlier years of development (e.g., Marchman \& Bates, 1994). However, it was also predicted that syntactic bootstrapping would be detected from approximately age 3;6 onwards, when grammatical knowledge is generally consolidated in most children. As for the prediction about the possible effect of the FR status on the associations between vocabulary and grammar development, the hypothesis is open, as to our knowledge no previous studies have explored this issue before. 


\section{Method}

\section{Participants}

The 54 children reported here are the participants of the prospective Tromsø Longitudinal Study of Dyslexia. All children were monolingual Norwegian, and had no known neurological conditions. There was no difference in general cognitive ability between the FR group (mean $=105.16, \mathrm{SD}=8.90$ ) and the NoFR group $($ mean $=108.64, \mathrm{SD}=9.28)(\mathrm{t}(51)=1.14, \mathrm{p}=.175)$ at age 24 months (Bayley, 2006).

The families were recruited from the arctic region of Norway via advertisements in local newspapers and brochures at local child health clinics. The families were selected in a three-stage procedure. In stage 1, parents who volunteered to participate in the study completed a short questionnaire. The questionnaire asked whether the parent had ever experienced reading and spelling problems and whether close relatives (i.e., their own parents and siblings) had experienced such problems (on a yes/no scale). In stage 2, parents were invited to a semi-structured interview. A detailed questionnaire was mailed to the parents before the interview. Parents who reported current impairments and/or a history of reading and writing impairments were asked to give a more detailed description in the interview. In stage 3, all parents were tested on a battery of literacy tests to validate their self-reported reading and spelling abilities. Parents were also tested on a wide battery of reading-related cognitive skills (see Nergård-Nilssen \& Hulme, 2014, for a more detailed description of the tests and procedures employed).

\section{Family risk (FR) group}

If one parent (or both) performed below -1 standard deviation on a composite score of standardized measures of reading fluency and spelling, and if this parent (or both) had a self-reported history of reading problems, children were allocated to the family risk group. Thirty-one children (11 girls, 20 boys) met these two criteria.

\section{No-family risk (NoFR) group}

Children whose parents performed within the normal range on standardised tests of reading fluency and spelling, and had no self-reported history of reading problems, were allocated to the No-FR group. Twenty-three children (11 girls, 12 boys) met these criteria.

\section{Parent characteristics}

Table 1 displays demographic variables and characteristics for FR and NoFR parents at the beginning of the study. NoFR parents had a significantly higher educational level compared to FR parents. The household income was however unaffected by differences in extent of education. There were no group differences in general ability (as indexed by Performance IQ). However, NoFR parents performed significantly better on verbal comprehension (WASI; Ørbeck \& Sundet, 2007) compared to FR parents, which may suggest that some parents in the FR group suffer from developmental language disorder in addition to dyslexia. There were also large group differences on tests measuring decoding (word-level reading) and spelling skills in FR and NoFR parents.

\section{Measures}

Table 2 shows the vocabulary and grammar measures used in the present study at the different time-points. 
Table 1. Demographic variables at the beginning of the study

\begin{tabular}{|c|c|c|c|c|c|c|c|c|}
\hline & \multicolumn{2}{|c|}{ NoFR parents } & \multicolumn{2}{|c|}{ FR parents } & \multirow[b]{2}{*}{$t$} & \multirow[b]{2}{*}{$d f$} & \multirow[b]{2}{*}{$p$} & \multirow{2}{*}{$\begin{array}{l}\text { Effect size } \\
\text { Cohen's }\end{array}$} \\
\hline & Mean & $S D$ & Mean & $S D$ & & & & \\
\hline Educational level & 3.17 & 0.85 & 2.85 & 0.87 & 1.99 & 118 & .049 & 0.37 \\
\hline Education after compulsory schooling & 4.06 & 2.91 & 3.22 & 2.74 & 1.51 & 109 & .133 & 0.29 \\
\hline Verbal Comprehension, mothers & 56.66 & 4.72 & 51.32 & 5.56 & 3.17 & 39 & .003 & 1.04 \\
\hline Verbal Comprehension, fathers & 57.56 & 3.62 & 52.08 & 4.50 & 4.07 & 38 & .000 & 1.34 \\
\hline
\end{tabular}

Note. Educational level (1 = compulsary school (year 1-10); 2 = upper secondary school / high school (year 11-13); $3=$ bachelor's degree; $4=$ master's degree and/or PhD). Education after compulsory schooling is indexed by number of years completed after Year 10 in lower secondary school. Performance IQ and Verbal Comprehension was assessed by Wechsler Abbreviated Scale of Intelligence (WASI; Ørbeck \& Sundet, 2007). Here, Verbal Comprehension is the mean raw score of Voabulary and Similarties. 
Table 2. Means, standard deviations, and group comparisons of children in lexical and grammatical measures

\begin{tabular}{|c|c|c|c|c|c|c|}
\hline & \multicolumn{2}{|c|}{ FR } & \multicolumn{2}{|c|}{ NoFR } & \multirow[b]{2}{*}{$t(52)$} & \multirow[b]{2}{*}{ Cohen's $d^{\mathrm{a}}$} \\
\hline & Mean & SD & Mean & SD & & \\
\hline \multicolumn{7}{|c|}{ Lexical measures } \\
\hline CDI, $1 ; 6$ & 42.81 & 38.07 & 37.17 & 27.90 & -0.60 & 0.17 \\
\hline CDI, 2;0 & 258.85 & 170.70 & 235.45 & 135.99 & -0.53 & 0.15 \\
\hline CDI, 2;6 & 464.90 & 162.48 & 489.26 & 156.63 & 0.55 & 0.15 \\
\hline CDI, 3;0 & 581.92 & 111.96 & 603.99 & 85.75 & 0.79 & 0.22 \\
\hline EVT, 3;6 & 46.12 & 13.16 & 48.61 & 11.88 & 0.72 & 0.20 \\
\hline CELF, 4;6 & 7.58 & 2.20 & 7.57 & 2.50 & -0.01 & 0.00 \\
\hline CELF, 6;0 & 10.85 & 2.40 & 12.27 & 1.95 & $2.33^{\star}$ & 0.66 \\
\hline \multicolumn{7}{|c|}{ Grammatical measures } \\
\hline CDI, $1 ; 6$ & 1.35 & 2.33 & 0.30 & 0.76 & $-2.08^{\star}$ & 0.61 \\
\hline CDI, 2;0 & 29.08 & 24.76 & 29.33 & 22.74 & 0.04 & 0.01 \\
\hline CDI, 2;6 & 58.75 & 25.40 & 62.70 & 28.87 & 0.53 & 0.14 \\
\hline CDI, 3;0 & 86.42 & 29.30 & 88.94 & 23.65 & 0.34 & 0.09 \\
\hline TROG, 3;6 & 27.36 & 13.48 & 25.47 & 13.81 & -0.50 & 0.14 \\
\hline TROG, 4;6 & 49.14 & 14.66 & 45.40 & 17.58 & -0.85 & 0.23 \\
\hline CELF, 4;6 & 25.63 & 8.82 & 27.83 & 11.16 & 0.81 & 0.22 \\
\hline CELF, 6;0 & 41.76 & 13.62 & 47.46 & 15.52 & 1.43 & 0.40 \\
\hline
\end{tabular}

Note. FR = family risk of dyslexia $(n=31)$; NoFR = no family risk of dyslexia $(n=23) ; S D=$ standard deviation; CDI = MacArthur-Bates Communicative Development Inventories (Fenson et al., 1993); EVT = Expressive Vocabulary Test, 2nd edition (Williams, 2007); CELF = Clinical Evaluation of Language Fundamentals, 4th edition (Semel et al., 2003); TROG = Test for Reception of Grammar, 2nd edition (Bishop, 2003).

a Effect size was estimated with Cohen's $d$ using the pooled standard deviation of the groups; * $p<.05$.

MacArthur-Bates Communicative Development Inventories: Words and sentences (CDI W\&S; Fenson et al., 1993; Norwegian adaptation by Kristoffersen \& Simonsen, 2012). Parents were asked to report on their child's expressive vocabulary and grammar at ages $1 ; 6,2 ; 0,2 ; 6$, and $3 ; 0$, respectively, by means of the CDI W\&S form. Items marked by parents as "word produced by the child" within each of the 22 semantic categories of the Vocabulary Checklist were summed to yield the 'CDI: Vocabulary score'. Similarly, items marked by parents within the Inflections Checklist (noun plurals and past tense forms) and the Grammatical Complexity Checklist (42 pairs of sentences, in which one sentence is in a more complex form than the other) were summed to yield the 'CDI: Grammar score'. Raw scores were used for the CDI outcomes. Reliability for the CDI W\&S scales varies between Cronbach's alpha $(\alpha)$ .74 and 1.00 (Kristoffersen \& Simonsen, 2012).

Expressive Vocabulary Test-2 (EVT-2). The EVT-2 Form A (Williams, 2007) was used to measure children's expressive vocabulary and word retrieval at age $3 ; 6$. Here, the examiner presented the child with a picture and a stimulus question, with 
stimulus words arranged in order of increasing difficulty. The child responded with a one-word label, answered a specific question, or provided a word that fitted the picture. Testing was discontinued when five consecutive items had been failed. The score here was the number of correct responses. Split-half reliability for EVT-2 Form A is $\alpha=.94$ (Williams, 2007).

Test for Reception of Grammar-2 (TROG-2; Bishop, 2003; Norwegian adaptation by Lyster \& Horn, 2009). This test was used to measure children's receptive grammar at ages 3;6 and 4;6, respectively. In this test, grammatical comprehension was assessed by using a multiple-choice format, where a picture depicting the target sentence is contrasted with three foils depicting a sentence that is altered by a grammatical or lexical element (Bishop, 2003). There is a block of four items for each grammatical contrast, and the block is passed if the child responds correctly to all four items. Blocks are arranged in order of increasing difficulty, and the test is discontinued after one error or more in five consecutive blocks. The score here is the number of correct responses. Internal reliability for the test is $\alpha=.95$ (Lyster \& Horn, 2009).

Clinical Evaluation of Language Fundementals-4 (CELF-4; Semel, Wiig, \& Secord, 2003; Norwegian adaptation by Monsrud \& Rygvold, 2013). Three subtests were administered to the children at ages 4;6 and 6;0, respectively: Expressive Vocabulary, henceforth called 'CELF: Vocabulary', was taken to evaluate the child's ability to name illustrations of people, objects, and actions (i.e., referential naming). Reliability for this scale is $\alpha=.82$ (Monsrud \& Rygvold, 2013). Further, the Word Structure subtest was used to evaluate the children's knowledge of grammatical rules in a sentence-completion task. Here, the child completes an orally presented sentence that pertains to an illustration, and is required to apply targeted word structure rules such as inflections and derivations. Reliability for this scale is $\alpha=.78$ (Monsrud \& Rygvold, 2013). Finally, the Formulated Sentences subtest was used to evaluate the ability to formulate compound and complex sentences when given grammatical (semantic and syntactic) constraints. Here, the child was asked to formulate a sentence, using target words or phrases, while using an illustration as a reference. Reliability for this scale is $\alpha=.94$ (Monsrud \& Rygvold, 2013). The Word Structure and the Formulated Sentences scores were combined into a composite score henceforth called 'CELF: Grammar'.

A composite grammar score based on the means of standardised scores from the TROG-2 $(\alpha=.96)$ and the two grammar subtests of CELF-4 (Word Structure, $\alpha=.92$ and Formulated sentences, $\alpha=.92$ ) was computed and used in the correlation analyses at age 4;6. The reliability for this composite score is $\alpha=.69$.

\section{Research design and general procedure}

The Tromsø Longitudinal Study of Dyslexia employs a repeated-measures design to monitor how the FR and NoFR group change over the passage of time. That is, children in the two groups undergo the same tests and procedures over a number of occasions. All children were tested at ages $1 ; 6,2 ; 0,2 ; 6,3 ; 0,3 ; 6,4 ; 6$, and 6;0, \pm 3 weeks. Thus, they were the same age at all assessment points.

All children were tested individually. Assessments were administered in a laboratory at the university and were videotaped and audio-recorded for later analyses. Each session lasted 2-3 hours and was completed with one examiner and one parent in the room (i.e., up to the age of 4;6). Parents received and completed the CDI form 
regarding their child's expressive vocabulary and grammar at home a day or two before the visit to the university laboratory. The CDI forms were inspected by the examiners at the clinic to identify possible errors.

\section{Results}

Altogether $70 \%$ of the participants had a full dataset of all language measures from ages $1 ; 6$ to $6 ; 0$. For the remainder, the number of missing values in language measures varied from 2 to $8(3.7-14.8 \%)$ due to non-attendance in separate assessments. However, according to Little's MCAR test, missing data was completely at random $\left(\chi^{2}(175)=\right.$ $160.34, \mathrm{p}>.05)$, enabling us to impute the missing values and retain all cases in the study. The multiple imputation option of the SPSS-program was used to impute the missing values. Linear regression was chosen as the method for imputation, and the mean of five imputations was used as a score for each missing value.

All distributions in lexical and grammatical measures approximated normal distribution, except at age $1 ; 6$, in which they were right skewed. Logarithmic transformation was applied for the CDI Vocabulary at $1 ; 6$, which corrected the right skewness of this measure. In the CDI Grammar at $1 ; 6,70 \%$ of the participants scored 0 , and a logarithmic transformation was unable to correct the skewness. As a consequence, it was recoded into three classes $(0=$ no, $1=1-3,2=5-8$ signs of grammar skills) to minimize skewness.

\section{Group differences in lexical and grammatical development}

Means, standard deviations, and group comparisons with independent sample t-tests in lexical and grammatical measures from ages 1;6 to 6;0 are presented in Table 2. The first research question, the similarity of lexical and grammatical growth in the two groups, was examined with Mixed-Design ANOVAs including age as the within-subjects factor and group (FR, NoFR) as the between-subjects factor. In the first Mixed-Design ANOVA using CDI Vocabulary from ages $1 ; 6$ to $3 ; 0$, the main effect of age was significant (F $\left.(3,50)=733.67, \mathrm{p}<.001, \eta_{\mathrm{p}}^{2}=.98\right)$, whereas the main effect of group and the interaction effect of time $\times$ group were not $\left(\mathrm{F}(1,52)=0.02, \mathrm{p}>.05, \eta_{\mathrm{p}}^{2}=.01\right.$, and $\mathrm{F}$ $(3,50)=1.02, p>.05, \eta_{\mathrm{p}}^{2}=.06$, respectively). Together, these results suggest that the level and growth of vocabulary was similar in the FR and NoFR groups between ages $1 ; 6$ and 3;0. In the second Mixed-Design ANOVA, vocabulary growth from ages $4 ; 6$ to $6 ; 0$ in the two groups was examined using CELF as the vocabulary measure. Again, the main effect of age was significant $\left(\mathrm{F}(1,52)=144.74, \mathrm{p}<.001, \eta_{\mathrm{p}}^{2}=.74\right)$, whereas the main effect of group was not $\left(\mathrm{F}(1,52)=1.78, \mathrm{p}>.05, \eta_{\mathrm{p}}^{2}=.03\right)$. However, between the ages of $4 ; 6$ and $6 ; 0$, the age $\times$ group interaction was also significant $(\mathrm{F}(1,52)=4.64$, $\left.\mathrm{p}<.05, \eta_{\mathrm{p}}^{2}=.08\right)$. Thus, between ages $4 ; 6$ and $6 ; 0$ the FR and NoFR groups started from a similar level of vocabulary, but the growth of it was steeper in the NoFR group. This steeper growth resulted in a significant group difference in the mean of CELF vocabulary at age 6;0 and a large effect size between the two groups (see Table 2).

In grammar, the similarity of growth in the FR and NoFR groups was examined with three Mixed-Design ANOVAs using CDI from ages $1 ; 6$ to 3;0, TROG from ages 3;6 to $4 ; 6$, and CELF from ages $4 ; 6$ to $6 ; 0$ as the grammar measure. In all these analyses the main effect of age was significant $\left(\mathrm{F}(3,50)=191.04, \mathrm{p}<.001, \eta_{\mathrm{p}}^{2}=.92 ; \mathrm{F}(1,52)=\right.$ $108.59, \mathrm{p}<.001, \eta_{\mathrm{p}}^{2}=.68$; and $\mathrm{F}(1,52)=150.54, \mathrm{p}<.001, \eta_{\mathrm{p}}^{2}=.74$, at ages $1 ; 6-3 ; 0$, $3 ; 0-3 ; 6$, and $4 ; 6-6 ; 0$, respectively), whereas the main effect of group and the 
interaction effect of time $\times$ group were not (age 1;6-3;0: $\mathrm{F}(1,52)=0.09, \mathrm{p}>.05, \eta_{\mathrm{p}}^{2}=.002$ and $\mathrm{F}(3,50)=0.92, \mathrm{p}>.05, \eta_{\mathrm{p}}^{2}=.01$, respectively; age $3 ; 0-3 ; 6: \mathrm{F}(1,52)=0.63, \mathrm{p}>.05$, $\eta_{\mathrm{p}}^{2}=.01$ and $\mathrm{F}(1,52)=0.21, \mathrm{p}>.05, \eta_{\mathrm{p}}^{2}=.004$, respectively; and age 4;6-6;0: $\mathrm{F}(1,52)=$ $1.65, \mathrm{p}>.05, \eta_{\mathrm{p}}^{2}=.03$ and $\mathrm{F}(1,52)=1.44, \mathrm{p}>.05, \eta_{\mathrm{p}}^{2}=.03$, respectively). Taken together, the results of Mixed-Design ANOVAs showed that the FR and NoFR groups started their grammar development at the same level and that the growth was also similar in the two groups throughout ages $1 ; 6$ to $6 ; 0$. However, according to the independent sample t-test, the difference in grammar skills was significant at age $1 ; 6$, and the effect size between the FR and NoFR group was moderate in CELF grammar at age 6;0 (see Table 2).

\section{Interdependencies between lexical and grammatical development}

Pearson correlations were used, first, to examine both concurrent and cross-lagged associations in lexical and grammatical measures, as well as between two consecutive assessment ages within one domain, i.e., vocabulary and grammar (see Tables 3 and 4 for correlations in the FR and NoFR group, respectively). Although there are some differences in the figures and significances of correlations between the FR and NoFR group, according to the Difference test based on Fisher's z-transformed correlation coefficients (McNemar, 1969), these two groups differed significantly only in four associations: the association was stronger in the FR-group between CDI vocabulary at ages $2 ; 0$ and $2 ; 6$, on the one hand, and between CDI vocabulary at 2;0 and CDI grammar at 3;0, on the other hand. Moreover, the association was stronger in the NoFR group between CDI grammar at 2;0 and TROG \& CELF grammar at 4;6, on the one hand, and TROG grammar at 3;6 and TROG \& CELF grammar at 4;6, on the other hand.

Regarding our second research question - interdependencies between lexical and grammatical domains in the FR and NoFR groups - the associations between lexical and grammatical measure are of special interest (please see the upper-right corner in Tables 3 and 4). Moderate to strong correlations, varying from .41 to .89 and .38 to .83 in the FR and NoFR group, respectively, were found between lexical and grammatical measures between ages $1 ; 6$ to $3 ; 0$. Moreover, moderate or strong associations between lexical and grammatical measures were found also within ages $3 ; 6$ to $6 ; 0$ : correlations varied between .36 and .62, and .49 and .63, in the FR and NoFR group, respectively. Finally, somewhat weaker and partly non-significant associations between the two domains were found when measures from the earlier age range (ages $1 ; 6$ to $3 ; 0)$ were correlated with measures from the later age $(3 ; 6$ to 6;0) (see Tables 3 and 4).

Significant correlations found between two consecutive time-points from vocabulary to grammar, or vice versa, do not, as such, stand for sufficient evidence of lexical or grammatical bootstrapping. Instead, concurrent and autoregressive associations need to be taken into account to find out the existence of significant cross-lagged associations. Therefore, the relations between lexical and grammatical measures were further modelled using the Mplus 8.0 program (Muthén \& Muthén, 1998-2017). Altogether, five different models, instead of one model including all language measures from ages $1 ; 6$ to $6 ; 0$, were constructed due to small sample sizes in the two groups. Two lexical and two grammatical measures from two consecutive time-points were included into the model at a time (e.g., CDI vocabulary at 1;6 and 2;0 and CDI grammar at $1 ; 6$ and $2 ; 0$ ). The time-window of 3;0-3;6 was not inspected, because vocabulary and grammar were measured differently in these two time-points, thus 
Table 3. Concurrent and predictive correlations between lexical and grammatical measures in children with family risk of dyslexia (FR group; $n=31$ )

\begin{tabular}{|c|c|c|c|c|c|c|c|c|c|c|c|c|c|}
\hline & 2. & 3. & 4. & 5. & 6. & 7. & 8. & 9. & 10. & 11. & 12. & 13. & 14. \\
\hline \multicolumn{14}{|l|}{ Lexical measures } \\
\hline 1. CDI, $1 ; 6$ & $0.73^{\star \star \star}$ & $0.69^{\star \star \star}$ & $0.53^{\star \star}$ & 0.14 & -0.14 & -0.14 & $0.65^{\star \star \star}$ & $0.68^{\star \star \star}$ & $0.41^{\star}$ & $0.65^{\star \star \star}$ & 0.16 & 0.09 & 0.17 \\
\hline 2. CDI, $2 ; 0$ & & $0.88^{\star \star \star}$ & $0.66^{\star \star \star}$ & 0.30 & -0.10 & -0.03 & $0.58^{\star \star \star}$ & $0.89^{\star \star \star}$ & $0.54^{\star \star}$ & $0.74^{\star \star \star}$ & 0.29 & 0.30 & $0.39^{\star}$ \\
\hline 3. CDI, $2 ; 6$ & & & $0.82^{\star \star \star}$ & $0.50^{\star \star}$ & 0.07 & 0.15 & $0.57^{\star \star \star}$ & $0.77^{\star \star \star}$ & $0.71^{\star \star \star}$ & $0.86^{\star \star \star}$ & $0.41^{*}$ & $0.38^{*}$ & $0.51^{\star \star}$ \\
\hline 4. CDI, 3;0 & & & & $0.55^{\star \star}$ & 0.08 & 0.22 & $0.46^{\star \star}$ & $0.55^{\star \star}$ & $0.70^{\star \star \star}$ & $0.83^{\star \star \star}$ & $0.48^{\star \star}$ & 0.32 & $0.40^{\star}$ \\
\hline 5. EVT, 3;6 & & & & & $0.39^{\star}$ & 0.26 & 0.20 & 0.25 & $0.59^{\star \star \star}$ & $0.53^{\star \star}$ & $0.53^{\star *}$ & $0.43^{\star}$ & $0.51^{\star \star}$ \\
\hline 6. CELF, 4;6 & & & & & & $0.46^{\star \star}$ & -0.17 & -0.17 & 0.14 & 0.07 & $0.36^{\star}$ & $0.62^{\star \star \star}$ & $0.60^{\star \star *}$ \\
\hline 7. CELF, $6 ; 0$ & & & & & & & 0.14 & -0.19 & 0.11 & 0.15 & -0.12 & 0.18 & $0.51^{\star \star}$ \\
\hline \multicolumn{14}{|c|}{ Grammatical measures } \\
\hline 8. CDI, $1 ; 6$ & & & & & & & & $0.53^{\star \star}$ & 0.28 & $0.56^{\star \star}$ & -0.08 & -0.02 & 0.16 \\
\hline 9. CDI, 2;0 & & & & & & & & & $0.54^{\star \star}$ & $0.62^{\star \star \star}$ & 0.16 & 0.18 & 0.26 \\
\hline 10. CDI, 2;6 & & & & & & & & & & $0.76^{\star \star \star}$ & $0.42^{*}$ & 0.25 & $0.40^{\star}$ \\
\hline 11. CDI, 3;0 & & & & & & & & & & & $0.42^{\star}$ & $0.40^{\star}$ & $0.49^{\star \star}$ \\
\hline 12. TROG, 3;6 & & & & & & & & & & & & $0.49^{\star \star}$ & 0.25 \\
\hline $\begin{array}{l}\text { 13. TROG } 4 ; 6 \& \\
\text { CELF, } 4 ; 6\end{array}$ & & & & & & & & & & & & & $0.64^{\star \star *}$ \\
\hline
\end{tabular}

Note. $\mathrm{CDI}=$ MacArthur-Bates Communicative Development Inventories (Fenson et al., 1993); EVT = Expressive Vocabulary Test, 2nd edition (Williams, 2007); CELF = Clinical Evaluation of Language

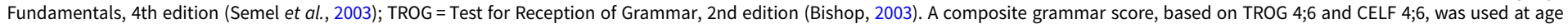
$4 ; 6 ;{ }^{\star} p<.05,{ }^{\star \star} p<.01,{ }^{\star \star \star} p<.001$. 
Table 4. Concurrent and predictive correlations between lexical and grammatical measures in children without family risk for dyslexia (NoFR group; $n=23$ )

\begin{tabular}{|c|c|c|c|c|c|c|c|c|c|c|c|c|c|}
\hline & 2. & 3. & 4. & 5. & 6. & 7. & 8. & 9. & 10. & 11. & 12. & 13. & 14. \\
\hline \multicolumn{14}{|l|}{ Lexical measures } \\
\hline 1. CDI, $1 ; 6$ & $0.64^{* * *}$ & $0.58^{\star \star}$ & $0.54^{\star \star}$ & 0.09 & -0.07 & -0.19 & $0.51^{*}$ & 0.38 & $0.46^{*}$ & $0.44^{*}$ & 0.25 & 0.21 & 0.09 \\
\hline 2. $\mathrm{CDI}, 2 ; 0$ & & $0.69^{\star \star \star}$ & 0.39 & $0.42^{*}$ & 0.24 & -0.23 & $0.43^{*}$ & $0.81^{\star \star \star}$ & $0.50^{*}$ & 0.33 & $0.55^{\star *}$ & $0.60^{* *}$ & $0.42^{*}$ \\
\hline 3. $\mathrm{CDI}, 2 ; 6$ & & & $0.83^{\star \star \star}$ & $0.52^{\star}$ & -0.06 & -0.29 & $0.44^{\star}$ & $0.67^{\star \star \star}$ & $0.83^{\star \star \star}$ & $0.76^{\star \star \star}$ & $0.49^{\star}$ & $0.45^{\star}$ & $0.42^{*}$ \\
\hline 4. CDI, $3 ; 0$ & & & & 0.36 & -0.05 & -0.14 & $0.43^{*}$ & 0.41 & $0.73^{\star \star \star}$ & $0.74^{\star \star \star}$ & 0.35 & 0.29 & 0.35 \\
\hline 5. EVT, $3 ; 6$ & & & & & $0.48^{*}$ & 0.04 & 0.33 & $0.43^{*}$ & $0.52^{*}$ & $0.48^{*}$ & $0.49^{\star}$ & $0.50^{*}$ & $0.61^{\star \star}$ \\
\hline 6. CELF, $4 ; 6$ & & & & & & $0.43^{*}$ & 0.27 & 0.15 & -0.03 & -0.07 & $0.49^{*}$ & $0.63^{* *}$ & $0.63^{\star * \star}$ \\
\hline 7. CELF, $6 ; 0$ & & & & & & & -0.13 & -0.25 & -0.19 & -0.12 & 0.09 & 0.10 & 0.16 \\
\hline \multicolumn{14}{|l|}{ Grammatical measures } \\
\hline 8. CDI, $1 ; 6$ & & & & & & & & 0.31 & 0.34 & 0.32 & 0.33 & 0.23 & 0.32 \\
\hline 9. CDI, $2 ; 0$ & & & & & & & & & $0.51^{*}$ & 0.26 & $0.63^{\star *}$ & $0.69^{\star * *}$ & $0.55^{\star \star}$ \\
\hline 10. CDI, 2;6 & & & & & & & & & & $0.84^{\star \star \star}$ & 0.40 & 0.35 & 0.34 \\
\hline 11. CDI, 3;0 & & & & & & & & & & & 0.23 & 0.14 & 0.24 \\
\hline 12. TROG, $3 ; 6$ & & & & & & & & & & & & $0.80^{\star \star \star}$ & $0.57^{\star \star}$ \\
\hline $\begin{array}{l}\text { 13. TROG } 4 ; 6 \text { \& CELF, } \\
4 ; 6\end{array}$ & & & & & & & & & & & & & $0.76^{\star \star \star}$ \\
\hline
\end{tabular}

Note. CDI = MacArthur-Bates Communicative Development Inventories (Fenson et al., 1993); EVT = Expressive Vocabulary Test, 2nd edition (Williams, 2007); CELF = Clinical Evaluation of Language Fundamentals, 4th edition (Semel et al., 2003); TROG = Test for Reception of Grammar, 2nd edition (Bishop, 2003). A composite grammar score, based on TROG 4;6 and CELF 4;6, was used at age $4 ; 6 ;{ }^{*} p<.05,{ }^{* *} p<.01,{ }^{\star * *} p<.001$ 
possibly violating the assumption of invariance of constructs assumed in panel models (Selig \& Little, 2012). Moreover, as 10 cross-lagged associations were inspected altogether, we guarded against type I error by using a strict significance level, .005 (traditional .05 divided by the number of examined cross-lagged paths). We started modelling at each time-window with a saturated model where all possible associations were estimated at the same time, i.e., concurrent, autoregressive, as well as cross-lagged paths. Next, each model was trimmed by removing non-significant cross-lagged paths using the .005 significance level as a criterion. Finally, group $\times$ vocabulary and group $\times$ grammar interaction variables were added, one by one, to the model to see whether the FR status had any additional effect on the cross-lagged associations. The parameters of all models were estimated using the MLR procedure due to slightly skewed distributions in some of the measures. The goodness of fit of the estimated model was evaluated using five indicators: the $\chi^{2}$ test, Comparative Fit Index (CFI), Tucker-Lewis Fit Index (TLI), Root Mean Square Error of Approximation (RMSEA), and Standardized Root Mean Square Residual (SRMR).

All significant cross-lagged associations between lexical and grammatical measures with standardized estimates of the loadings are presented in Figure 1. All models fitted the data well (see Figure 1 for the fit-indices presented separately for each model). Results showed, first, that within the early years $(1 ; 6$ to $3 ; 0)$ two cross-lagged correlations from vocabulary to grammar were significant: CDI Vocabulary at $1 ; 6$ explained $32 \%$ of the variance in CDI Grammar at 2;0, and CDI Vocabulary at 2;6 explained $34 \%$ of the variance in CDI Grammar at 3;0. Second, one significant cross-lagged correlation from grammar to vocabulary was found, namely CDI Grammar at $2 ; 0$ explained $14 \%$ of the variance in CDI Vocabulary at $2 ; 6$. Third, between ages $3 ; 6$ and $6 ; 0$, only two significant cross-lagged associations were found, both from grammar to vocabulary: first, age 3;6 grammar explained $11 \%$ of the variance in age $4 ; 6$ vocabulary, and age $4 ; 6$ grammar explained $38 \%$ of the variance in age 6;0 vocabulary. All other cross-lagged associations were non-significant. Finally, all group $\times$ vocabulary and group $\times$ grammar interaction effects on cross-lagged association were non-significant, suggesting that FR status had no additional effect on any of the cross-lagged associations. The only significant effect of group was found at age 6;0, where a negative association between FR status and vocabulary, on the one hand, and grammar, on the other hand, was found, suggesting that having family risk for dyslexia resulted in lower scores in both vocabulary and grammar at age 6;0.

\section{Discussion}

Employing a longitudinal multiple-wave design, the first aim of this study was to investigate whether the growth of lexical and grammatical skills was similar in children with and without a familial risk of dyslexia between the ages of $1 ; 6$ and 6;0. In line with our expectations, neither lexical nor grammatical development differed significantly between the groups at earlier ages, except for grammar at age 1;6. It appeared that this effect size was large due to the very small variances observed in both groups, as two-thirds of the children scored 0 points in grammar at this very early stage of expressive grammar. On the other hand, the FR group seemed to achieve lower scores when tested at the end of the preschool period (i.e., age 6;0), which yielded moderate to large effects in grammar and vocabulary, respectively. This pattern of results does not align well with those who reported early group-level 


\section{VOCABULARY}
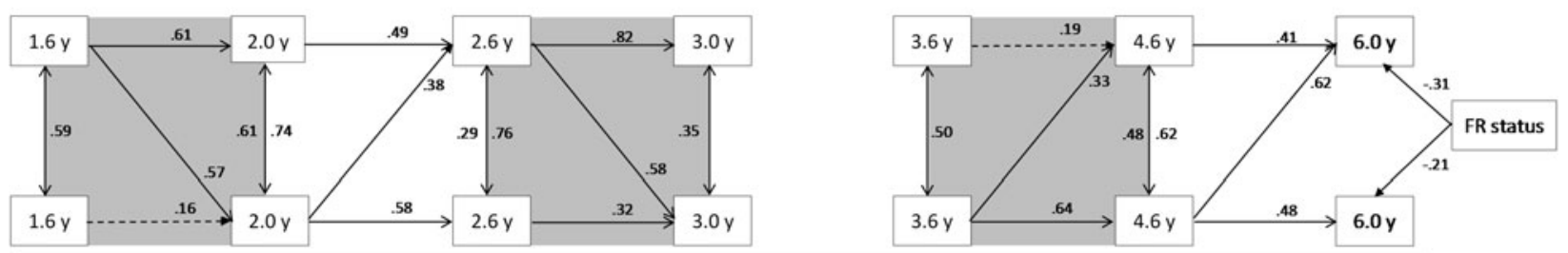

GRAMMAR

\section{$\mathrm{CFI}=1.0 \mathrm{TU}=1.00$ \\ $=1.00 \quad C F=1.00 \quad \mathrm{TU}=1.00$ \\ RMSEA $=.000$, SRMR $=.00$ \\ CFI $=1.00$ TU $=1.00$
RMSEA $=.000$, SRMR \\ CFI $=0.98 \quad \mathrm{Tu}=0.92$ \\ RMSEA $=.171$, SRMR $=.022$}

$\mathrm{chi}^{2}=0.66(\mathrm{df}=1) \mathrm{p}=.42$

\section{$\mathrm{CFI}=0.98 \mathrm{TU}=0.90$}

RMSEA $=.135$, SRMR $=.040$ $c i^{2}=1.98(d f=1) p=.16$

\section{$C F \mathrm{I}=0.97 \mathrm{TU}=0.95$}

RMSEA $=092$, SRMR $=0.035$ $c \mathrm{~h}^{2}=5.84(\mathrm{df}=4) \mathrm{p}=.21$

Figure 1. Concurrent, auto-regressive and cross-lagged associations between vocabulary and grammar. All significant paths are presented with solid line and non-significant with dash line together with standardized estimates of the loadings.

Note.

Altogether six different models were constructed: two consecutive ages were included in one model due to small sample size (gray and white rectangles). 
differences that diminished at later ages. For example, Chen et al. (2017) found a significant difference between total vocabulary scores of the groups only when they were 19-20 months old, and this led the authors to argue for a critical age window, after which the differences might be difficult to discern. In a similar vein, Nash et al. (2013) observed that the FR group performed worse on vocabulary and grammar tasks at age 3;6, but that their performance was like that of the NoFR group at age $4 ; 6$. The discrepancy between our results and these FR study results might be in part due to the small sample size of our NoFR group, which limited the statistical power needed to detect subtle between-group differences at earlier ages. However, it is important to highlight that group sizes were similar throughout the observation period. Thus, the small sample size cannot fully account for why group-level differences reached significance later rather than earlier in development.

One factor that could explain the inconsistent results of lexical and grammatical skills in FR children may have to do with the extent to which different samples with FR contain children who also show symptoms of developmental language disorder (e.g., difficulties in acquiring words and sentences), due to the well-documented overlap between dyslexia and DLD (Bishop \& Snowling, 2004; Snowling \& Hulme, 2012; Snowling \& Melby-Lervåg, 2016). Given that the degree of this comorbidity reported in the literature varies between samples (e.g., Catts et al., 2005; Nash et al., 2013), it might be argued that vocabulary and grammar deficits could manifest earlier in FR samples which include a relatively higher percentage of children with non-phonological language difficulties. Likewise, the varying number of FR children who later turn out to be dyslexic in different samples may also be responsible for the contradictory results. Problems in broader language skills have mostly been observed in FR children who later developed dyslexia (Snowling \& Melby-Lervåg, 2016; van Viersen et al., 2018), suggesting that FR samples that comprise a higher number of FR children with dyslexia might be expected to yield significant group-level differences at early ages. It is also worth mentioning that divergent findings could be attributed to various methodological issues (e.g., data obtained from independent samples vs. same sample of children, utilizing parental reports vs. standardised tests), as well as to different background characteristics of the participating children, such as their native languages. However, as stated earlier, Norwegian is a Germanic language with a similar morphological and syntactical structure to that of English. Therefore, we do not assume that the native language of the current sample would lead to significantly deviant results from the previously reported ones.

The developmental trend observed here might also be related to the magnitude of genetic and environmental influences on language skills, which was shown to change with development (Hayiou-Thomas, Dale, \& Plomin, 2012). There is evidence that the genetic influences become increasingly important for variation in language abilities as children get older, whereas the shared environmental effects, which were substantial on early language, become weaker over time (e.g., Hayiou-Thomas et al., 2012; Stromswold, 2001). The fact that all of the participating children, except one who started at a later age, were attending a daycare centre from they were around age 1;0 could have had an equalizing effect on the variation of children's early language skills. Our results might thus suggest that the effect of this shared environment became less influential with age, while the genetic effect of FR increased, resulting in significant difference between the groups towards the end of early childhood.

In fact, in Lyytinen and Lyytinen's (2004) study, results generally supporting this line of thinking were found. Although the group-level differences reached significance 
earlier compared to the current findings, possibly due to the reasons discussed above, FR and NoFR children performed similarly at earlier assessment points (i.e., ages 2;0 and 2;6). However, at age 3;6, FR children had significantly lower scores on lexicon and grammar than their NoFR peers, and between-group differences were significant at age 5;0 as well. The authors suggested a developmental trend according to which delays and deficits in the lexical and grammatical skills of FR children might become more evident with increasing age. A possible reason postulated for this result is that subtle difficulties in speech perception are often present in FR children, and the cumulative effects of these difficulties may be observed in some areas of linguistic development, including vocabulary and expressive language (Lyytinen \& Lyytinen, 2004). Indeed, recent research has revealed that speech perception deficit could implicate a deficient development of phonological representations and was related to later poor language skills in FR children (Lohvansuu et al., 2018; Snowling et al., 2019). Therefore, a rather comprehensive account, which suggests that poor phonological skills cause a bottleneck in language processing that can lead to adverse cascading effects on the development of vocabulary and grammar (Catts \& Adlof, 2011), may also have the potential to explain why FR children, as a group, seem to develop relatively lower skills in vocabulary and grammar over time.

The current results also suggest some parallels with recent evidence, which indicated a significant association between being at family risk of dyslexia and late-emerging language difficulties (Snowling et al., 2016; Zambrana et al., 2014). These studies reported that, although showing comparable early language skills to those of their NoFR peers, a number of FR children seemed to develop language difficulties later in childhood. Snowling et al. (2016) argue that these results might be suggestive of a different aetiology, possibly of genetic origin, which leads to atypical language trajectories in some FR children. Therefore, it might be that some of the children in the FR group had late-onset delay, particularly in vocabulary between ages $4 ; 6$ and 6;0, which resulted in a significant difference with a large effect size between the FR and NoFR groups at age 6;0. Despite failing to reach significance, the effect size between the groups was moderate in grammar at this age, suggesting that some of these FR children might also show late-onset delay in grammar, though to a lower degree than in the vocabulary domain. The children in this study have not been tested for language impairment yet. However, it is noteworthy that the parents of FR children had significantly lower scores on verbal comprehension (WASI; Ørbeck \& Sundet, 2007) than did NoFR parents, and this may suggest that several of these FR children might be at risk for language impairment. Furthermore, a large body of evidence suggest that problems in oral language development are among the significant risk factors underpinning later reading difficulties (Hulme et al., 2015). Thus, our findings point to the importance of having a continued focus on the language development of FR children in the years preceding school entry for enhancing the possibility of early detection of those who are at high risk of reading problems.

\section{Concurrent and cross-lagged associations between vocabulary and grammar}

The second aim of this study was to examine the pattern of developmental interdependencies between these skills and to explore whether FR status exerts an effect on the associations between vocabulary and grammar. Our analyses regarding the concurrent correlations between lexical and grammatical measures revealed, as expected, significant associations. These contemporaneous relations, which were 
consistently strong over the course of the preschool period, suggest that lexicon and grammar appear to develop in tandem in both FR and NoFR children. They extend previous findings, which found a tight link between these constructs, particularly in the early years of language development (i.e., up to approximately age 3;0; e.g., Bates \& Goodman, 2001; Braginsky et al., 2015; Thordardottir et al., 2002), by showing a close relationship between them also from ages $4 ; 6$ to 6;0.

As regards the question of directional effects between vocabulary and grammar development across time, our results provided evidence for both lexical and syntactic bootstrapping between ages $1 ; 6$ and 6;0. Despite detecting a significant negative relation between FR status and vocabulary and grammar scores at the last assessment point (i.e., 6;0), we found no effect of group status on the cross-lagged associations. This finding suggests that children in this study had a similar pattern of development with respect to the temporal direction of the relationship between vocabulary and grammar, regardless of whether they had a family history of dyslexia or not. Previous research suggests that difficulties in vocabulary and grammar might be more related to dyslexia status rather than to FR status (Snowling \& Melby-Lervåg, 2016; van Viersen et al., 2018), and this may explain the non-significant differences in cross-lagged associations between the two groups to some extent. However, since the present study is the first to examine this issue, our results need to be replicated in future studies.

During the period from ages $1 ; 6$ to $3 ; 0$, evidence of a significant association of early vocabulary knowledge with subsequent grammar emerged between ages $1 ; 6$ and 2;0, and also between 2;6 and 3;0. These findings provide support for lexical bootstrapping, suggesting that children who make more gains in expressive vocabulary tend to also make large gains in grammar during the following time period. Our observation that lexical skills at $1 ; 6$ predicted grammatical growth at 2;0, rather than the reverse, seems to be consistent with the critical mass hypothesis (Marchmann \& Bates, 1994), according to which growth in syntactic and morphological structures in the early stages of language development depends on the extent of expressive vocabulary. Since the earlier studies with a similar design to ours did not include children who were younger than age $2 ; 0$, the current results extend the cross-lagged findings of past research to a younger age. In addition, analyses revealed syntactic bootstrapping between ages $2 ; 0$ and 2;6, suggesting that children's prior grammatical skills contribute to the subsequent development of their lexical skills. This result might be due to the fact that most children typically produce their multiword utterances by 24 months, and this development can influence subsequent lexical acquisition significantly.

Before going any further, an important point regarding the observed temporal ordering in the acquisition of lexicon and grammar should be mentioned. It has been argued that this pattern of data could simply arise from the measurement properties of the CDI inventory, which is widely used to assess early language development (Hoff et al., 2018). That is to say, an observed ordering relation between two variables might indeed be an artefact of a non-linear mapping between a construct and its measure rather than a true reflection of the relationship between those variables (Dixon \& Marchman, 2007). However, compelling evidence from multivariate genetic analyses suggests substantial genetic correlation between the CDI vocabulary and grammar scales (Dale et al., 2000) justifying the use of the CDI to assess language development in toddlerhood. Furthermore, being compatible with bootstrapping mechanisms, statistical learning accounts also provide some support 
for the observation that lexical growth drives grammatical development in the earliest stages of language acquisition. According to statistical language learning, children are sensitive to the probability with which syllables co-occur in their phonological input, and by making use of this information they are able move from surface structure to deeper structure, such as tracking syllables to find words and then an underlying grammar to learn about phrasal units (Romberg \& Saffran, 2010; Thiessen, 2017).

From age $3 ; 6$ to school entry age, children displayed two significant cross-lagged correlations, both consistent with syntactic bootstrapping. In line with our expectations, we found evidence that level of children's grammar predicted subsequent growth in their vocabulary from ages $3 ; 6$ to $4 ; 6$, and from ages $4 ; 6$ to $6 ; 0$, suggesting a greater influence of grammatical skills on the development of vocabulary knowledge than vice versa during this period. These results might be a reflection of the fact most children display a burst in their grammatical development during the third and fourth years of life, adding passives, relative clauses, and other complex forms (Bates \& Goodman, 2001). Moreover, our finding of lexical bootstrapping and syntactic bootstrapping occurring between ages $1 ; 6$ and $6 ; 0$ provides some partial support for the notion of bi-directional bootstrapping, which suggests that the two constructs contribute to development of one another across time. Unlike some previous research (Dionne et al., 2003; Moyle et al., 2007), which demonstrated bi-directional bootstrapping due to lexical and syntactic bootstrapping co-occurring in the same time period, the current bootstrapping processes occurred in a sequential fashion rather than simultaneously over time. However, different time intervals between measurement occasions that were used to explore bootstrapping effects in these two studies as well as in the Hoff et al. (2018) study, do not overlap well with ours, which in turn make the results relatively less comparable. That said, in agreement with a framework of development discussed by Hirsh-Pasek, Tucker, and Golinkoff (1996), we suggest that considering the potential contribution of lexical growth to grammatical growth and vice versa "as systems of developing knowledge that are mutually informing and always available, but with differing weights along the developmental trajectory" (p. 464) might also help to explain why bootstrapping was detected only at certain ages and in differing directions in young children.

Although strengthened by the longitudinal nature of the study, and the statistical modelling taking this into account, some limitations of the present data should be pointed out. First, the relatively small sample size of the groups may have limited the ability to detect small directional influences between vocabulary and grammar domains, as well as differences between the groups. Therefore, further research with a larger sample is needed for broader generalisations. Second, it is important to emphasise that, although they provide valuable insights into the possible temporal effects of the variables over time, cross-lagged panel analyses remain correlational. As such, we cannot rule out the possibility of third-variable explanations for the observed effects (Morgan \& Winship, 2014), and draw causal inferences from the current findings. Therefore, intervention research designed to establish the directionality of the causal interaction between vocabulary and grammar would be a valuable future direction.

Third, we applied single, relatively coarse-grained tests to assess lexical and grammatical knowledge (except for utilizing two grammar tests at age 4;6), which means that our results are necessarily limited by these particular measures. Had resources allowed, multiple measures for each construct at all time-points would have been preferable. However, it should be noted that the measures selected for this study were reported to have good internal consistency and test-retest reliability. 
Fourth, FR and NoFR parents differed in terms of their educational level. However, family income did not appear to be affected by this difference. Several studies have pointed towards a relation between children's language ability across domains and the socioeconomic status (SES) of their families (see Pace, Lou, Hirsh-Pasek, \& Golinkoff, 2017, for a review). Because the children in the current study come from families with similar SES backgrounds, and the level of education in both groups was generally high, we do not assume that this educational level difference would lead to differences between the FR and NoFR children's language outcomes. Future studies might consider involving a more representative sample of families with low SES, as this could reveal different results from ours.

Overall, given the findings that the FR group performed more poorly than the NoFR group, particularly on vocabulary but also, though to a lesser degree, on grammar at school entry age, it may be argued that some of the FR children are more at risk of developing reading impairment and thus more in need of early intervention. Relatedly, it may also prove useful to monitor the language development of children with a family history of dyslexia, even though they seem to be showing typical early oral language skills. Moreover, current results did not reveal an effect of FR status on the temporal relationship between lexicon and grammar across time, suggesting that it might be the dyslexia outcome rather than the FR status which has a significant effect on the bootstrapping mechanisms in at-risk children. Due to the longitudinal nature of the study, in future work we will be able to investigate this hypothesis.

Author ORCIDs. (D) Ømur CAGLAR-RYENG, 0000-0001-9127-8750

Acknowledgements. This study was supported by a grant from the Tromsø Research Foundation (grant number A42966) to the third author of the paper. We thank all families who took part in the study.

\section{References}

Bates, E., Bretherton, I., \& Snyder, L. (1988). From first words to grammar: individual differences and dissociable mechanisms. Cambridge University Press.

Bates, E., \& Goodman, J. C. (2001). On the inseparability of grammar and the lexicon: evidence from acquisition. In M. Tomasello \& E. Bates (Eds.), Language development: the essential readings (pp. 134-62). Oxford: Blackwell.

Bayley, N. (2006). Bayley Scales of Infant and Toddler Development (3rd ed.). San Antonio, TX: Harcourt Assessment.

Bernal, S., Lidz, J., Millotte, S., \& Christophe, A. (2007). Syntax constrains the acquisition of verb meaning. Language Learning and Development, 3(4), 325-41.

Bishop, D. V. M. (2003). The Test for Reception of Grammar (2nd ed.). London: Pearson.

Bishop, D. V., \& Snowling, M. J. (2004). Developmental dyslexia and specific language impairment: Same or different? Psychological Bulletin, 130(6), 858-86.

Bishop, D. V., Snowling, M. J., Thompson, P. A., Greenhalgh, T., Catalise-2 Consortium, Adams, C., ... \& Boyle, C. (2017). Phase 2 of CATALISE: a multinational and multidisciplinary Delphi consensus study of problems with language development: terminology. Journal of Child Psychology and Psychiatry, 58 (10), 1068-80.

Braginsky, M., Yurovsky, D., Marchman, V. A., \& Frank, M. C. (2015). Developmental changes in the relationship between grammar and the lexicon. In D. C. Noelle, R. Dale, A. S. Warlaumont, J. Yoshimi, T. Matlock, C. D. Jennings, \& P. P. Maglio (Eds.), Proceedings of the 37th Annual Meeting of the Cognitive Science Society (pp. 256-61). Austin, TX: Cognitive Science Society.

Carroll, J. M., Mundy, I. R., \& Cunningham, A. J. (2014). The roles of family history of dyslexia, language, speech production and phonological processing in predicting literacy progress. Developmental Science, 17(5), 727-42. 
Catts, H. W., \& Adlof, S. (2011). Phonological and other language deficits associated with dyslexia. In C. A. Fowler, D. Braze, \& S. A. Brady (Eds.), Explaining individual differences in reading: theory and evidence (pp. 137-51). New York: Psychology Press.

Catts, H. W., Adlof, S. M., Hogan, T. P., \& Weismer, S. E. (2005). Are specific language impairment and dyslexia distinct disorders? Journal of Speech, Language, and Hearing Research, 48(6), 1378-96.

Chen, A., Wijnen, F., Koster, C., \& Schnack, H. (2017). Individualized early prediction of familial risk of dyslexia: a study of infant vocabulary development. Frontiers in Psychology, 8(156). doi:10.3389/ fpsyg.2017.00156

Dale, P. S., Dionne, G., Eley, T. C., \& Plomin, R. (2000). Lexical and grammatical development: a behavioural genetic perspective. Journal of Child Language, 27(3), 619-42.

Dionne, G., Dale, P. S., Boivin, M., \& Plomin, R. (2003). Genetic evidence for bidirectional effects of early lexical and grammatical development. Child Development, 74(2), 394-412.

Dixon, J. A., \& Marchman, V. A. (2007). Grammar and the lexicon: developmental ordering in language acquisition. Child Development, 78(1), 190-212.

Erickson, L. C., \& Thiessen, E. D. (2015). Statistical learning of language: theory, validity, and predictions of a statistical learning account of language acquisition. Developmental Review, 37, 66-108.

Fenson, L., Dale, P. S., Reznick, J. S., Thal, D., Bates, E., Hartung, J. P., ... Reilly, J. S. (1993). The MacArthur Communicative Development Inventories: user's guide and technical manual. San Diego, CA: Singular Publishing Group.

Gallagher, A., Frith, U., \& Snowling, M. J. (2000). Precursors of literacy delay among children at genetic risk of dyslexia. Journal of Child Psychology and Psychiatry and Allied Disciplines, 41(2), 203-13.

Gleitman, L. (1990). The structural sources of verb meanings. Language Acquisition, 1(1), 3-55.

Hayiou-Thomas, M. E., Dale, P. S., \& Plomin, R. (2012). The etiology of variation in language skills changes with development: a longitudinal twin study of language from 2 to 12 years. Developmental Science, 15(2), 233-49.

Hirsh-Pasek, K., Tucker, M., \& Golinkoff, R. M. (1996). Dynamic systems theory: reinterpreting 'prosodic bootstrapping' and its role in language acquisition. In J. L. Morgan \& K. Demuth (Eds.), Signal to syntax: bootstrapping from speech to grammar in early acquisition (pp. 449-66). Mahwah, NJ: Lawrence Erlbaum Associates.

Hoff, E., Quinn, J. M., \& Giguere, D. (2018). What explains the correlation between growth in vocabulary and grammar? New evidence from latent change score analyses of simultaneous bilingual development. Developmental Science, 21(2), e12536.

Hohle, B. (2009). Bootstrapping mechanisms in first language acquisition. Linguistics, 47(2), 359-82.

Hulme, C., Nash, H. M., Gooch, D., Lervåg, A., \& Snowling, M. J. (2015). The foundations of literacy development in children at familial risk of dyslexia. Psychological Science, 26(12), 1877-86.

Koster, C., Been, P. H., Krikhaar, E. M., Zwarts, F., Diepstra, H. D., \& van Leeuwen, T. H. (2005). Differences at 17 months: productive language patterns in infants at familial risk for dyslexia and typically developing infants. Journal of Speech, Language, and Hearing Research, 48(2), 426-38.

Kristoffersen, K. E., \& Simonsen, H. G. (2012). Tidlig språkutvikling hos norske barn: MacArthur-Bates foreldrerapport for kommunikativ utvikling [Early language development in Norwegian children: MacArthur-Bates Communicative Development Inventories]. Oslo: Novus.

Lervåg, A., Bråten, I., \& Hulme, C. (2009). The cognitive and linguistic foundations of early reading development: a Norwegian latent variable longitudinal study. Developmental Psychology, 45(3), 764-81.

Lohvansuu, K., Hämäläinen, J. A., Ervast, L., Lyytinen, H., \& Leppänen, P. H. (2018). Longitudinal interactions between brain and cognitive measures on reading development from 6 months to 14 years. Neuropsychologia, 108, 6-12.

Lyster, S. A. H, \& Horn, E. (2009). Norsk håndbok for Test for Reception of Grammar-2 [Norwegian Manual of Test for Reception of Grammar-2]. Stockholm: 08 Tryck AB.

Lyytinen, H., Aro, M., Eklund, K., Erskine, J., Guttorm, T., Laakso, M. L., ... \& Torppa, M. (2004). The development of children at familial risk for dyslexia: birth to early school age. Annals of Dyslexia, 54(2), 184-220.

Lyytinen, P., \& Lyytinen, H. (2004). Growth and predictive relations of vocabulary and inflectional morphology in children with and without familial risk for dyslexia. Applied Psycholinguistics, 25(3), 397-411.

Marchman, V. A., \& Bates, E. (1994). Continuity in lexical and morphological development: a test of the critical mass hypothesis. Journal of Child Language, 21(2), 339-66. 
Marchman, V. A., Martínez-Sussmann, C., \& Dale, P. S. (2004). The language-specific nature of grammatical development: evidence from bilingual language learners. Developmental Science, 7(2), 212-24.

McNemar, Q. (1969). Psychological statistics (4th ed.). New York: John Wiley and Sons.

Monsrud, M.-B., \& Rygvold, A.-L. (2013). Clinical Evaluation of Language Fundamentals-4 [Norwegian adaptation]. Stockholm: Pearson Assessment.

Morgan, S. L., \& Winship, C. (2014). Counterfactuals and causal inference: methods and principles for social research (2nd ed.). New York: Cambridge University Press.

Moyle, M. J., Weismer, S. E., Evans, J. L., \& Lindstrom, M. J. (2007). Longitudinal relationships between lexical and grammatical development in typical and late-talking children. Journal of Speech, Language, and Hearing Research, 50(2), 508-28.

Muthén, L. K., \& Muthén, B. O. (1998-2017). Mplus users' guide (8th ed.). Los Angeles, CA: Muthén \& Muthén.

Naigles, L. (1990). Children use syntax to learn verb meanings. Journal of Child Language, 17(2), 357-74.

Naigles, L. G., \& Kako, E. T. (1993). First contact in verb acquisition: defining a role for syntax. Child Development, 64(6), 1665-87.

Naigles, L. R., \& Swensen, L. D. (2007). Syntactic supports for word learning. In E. Hoff \& M. Shatz (Eds.), Blackwell handbook of language development (pp. 212-31). Oxford: Blackwell.

Nash, H. M., Hulme, C., Gooch, D., \& Snowling, M. J. (2013). Preschool language profiles of children at family risk of dyslexia: continuities with specific language impairment. Journal of Child Psychology and Psychiatry, 54(9), 958-68.

Nergård-Nilssen, T., \& Hulme, C. (2014). Developmental dyslexia in adults: behavioural manifestations and cognitive correlates. Dyslexia, 20(3), 191-207.

Ørbeck, B., \& Sundet, K. S. (2007). WASI [Wechsler Abbreviated Scale of Intelligence, Norwegian version]. Stockholm: Harcourt Assessment.

Pace, A., Luo, R., Hirsh-Pasek, K., \& Golinkoff, R. M. (2017). Identifying pathways between socioeconomic status and language development. Annual Review of Linguistics, 3, 285-308.

Romberg, A. R., \& Saffran, J. R. (2010). Statistical learning and language acquisition. Wiley Interdisciplinary Reviews: Cognitive Science, 1(6), 906-14.

Saffran, J. R., \& Wilson, D. P. (2003). From syllables to syntax: multilevel statistical learning by 12-month-old infants. Infancy, 4(2), 273-84.

Selig, J. P., \& Little, T. D. (2012). Autoregressive and cross-lagged panel analysis for longitudinal data. In B. Laursen, T. D. Little, \& N. A. Card (Eds.), Handbook of developmental research methods (pp. 265-78). London: Guilford Press.

Semel, E., Wiig, E. H., \&Secord, W. A. (2003). Clinical Evaluation of Language Fundamentals (4th ed.). San Antonio, TX: Harcourt Assessment.

Simonsen, H. G., Kristoffersen, K. E., Bleses, D., Wehberg, S., \& Jørgensen, R. N. (2014). The Norwegian Communicative Development Inventories: reliability, main developmental trends and gender differences. First Language, 34(1), 3-23.

Snowling, M. J., Duff, F. J., Nash, H. M., \& Hulme, C. (2016). Language profiles and literacy outcomes of children with resolving, emerging, or persisting language impairments. Journal of Child Psychology and Psychiatry, 57(12), 1360-9.

Snowling, M. J., Gallagher, A., \& Frith, U. (2003). Family risk of dyslexia is continuous: individual differences in the precursors of reading skill. Child Development, 74(2), 358-73.

Snowling, M. J., Gooch, D., McArthur, G., \& Hulme, C. (2018). Language skills, but not frequency discrimination, predict reading skills in children at risk of dyslexia. Psychological Science, 29(8), 1270-82.

Snowling, M. J., \& Hulme, C. (2012). Annual research review: the nature and classification of reading disorders - a commentary on proposals for DSM-5. Journal of Child Psychology and Psychiatry, 53(5), 593-607.

Snowling, M. J., Lervåg, A., Nash, H. M., \& Hulme, C. (2019). Longitudinal relationships between speech perception, phonological skills and reading in children at high-risk of dyslexia. Developmental Science, 22 (1), e12723.

Snowling, M. J., \& Melby-Lervåg, M. (2016). Oral language deficits in familial dyslexia: a meta-analysis and review. Psychological Bulletin, 142(5), 498-545. 
Stromswold, K. (2001). The heritability of language: a review and metaanalysis of twin, adoption, and linkage studies. Language, 77(4), 647-723.

Thiessen, E. D. (2017). What's statistical about learning? Insights from modelling statistical learning as a set of memory processes. Philosophical Transactions of the Royal Society B: Biological Sciences, 372(1711). doi:org/10.1098/rstb.2016.0056

Thompson, P. A., Hulme, C., Nash, H. M., Gooch, D., Hayiou-Thomas, E., \& Snowling, M. J. (2015). Developmental dyslexia: predicting individual risk. Journal of Child Psychology and Psychiatry, 56(9), 976-87.

Thordardottir, E. T., Weismer, S. E., \& Evans, J. L. (2002). Continuity in lexical and morphological development in Icelandic and English-speaking 2-year-olds. First Language, 22(1), 3-28.

Torppa, M., Lyytinen, P., Erskine, J., Eklund, K., \& Lyytinen, H. (2010). Language development, literacy skills, and predictive connections to reading in Finnish children with and without familial risk for dyslexia. Journal of Learning Disabilities, 43(4), 308-21.

van Bergen, E., van der Leij, A., \& de Jong, P. F. (2014). The intergenerational multiple deficit model and the case of dyslexia. Frontiers in Human Neuroscience, 8(346). doi:10.3389/fnhum.2014.00346

van Viersen, S., de Bree, E. H., Verdam, M., Krikhaar, E., Maassen, B., van der Leij, A., \& de Jong, P. F. (2017). Delayed early vocabulary development in children at family risk of dyslexia. Journal of Speech, Language, and Hearing Research, 60(4), 937-49.

van Viersen, S., de Bree, E. H., Zee, M., Maassen, B., van der Leij, A., \& de Jong, P. F. (2018). Pathways into literacy: the role of early oral language abilities and family risk for dyslexia. Psychological Science, 29 (3), 418-28.

Weissenborn, J., \& Hohle, B. (2001). Introduction. In J. Weissenborn \& B. Hohle (Eds.), Approaches to bootstrapping: phonological, lexical, syntactic and neurophysiological aspects of early language acquisition, Vol. 1 (pp. vii-xvii). Amsterdam: John Benjamins.

Williams, K. T. (2007). Expressive Vocabulary Test (2nd ed.). Bloomington, MN: Pearson.

Zambrana, I. M., Pons, F., Eadie, P., \& Ystrom, E. (2014). Trajectories of language delay from age 3 to 5 : persistence, recovery and late onset. International Journal of Language \& Communication Disorders, 49 (3), 304-16.

Cite this article: Caglar-Ryeng $\varnothing$, Eklund K, Nergård-Nilssen T (2019). Lexical and grammatical development in children at family risk of dyslexia from early childhood to school entry: a cross-lagged analysis. Journal of Child Language 46, 1102-1126. https://doi.org/10.1017/S0305000919000333 